\title{
PANORAMA DE LA NARRATIVA Y POESÍA BOLIVIANAS
}

POR

Luis H. Antezana J.

Los años 70 y 80 carecen de una cronología 'literariamente' motivada en Bolivia como, creo, en gran parte del continente- pues no es posible discernir, en el sentido tradicional de término, "movimientos" o iniciativas más o menos programáticos que permitieran marcar $x$ origen de y proceso literario. Surgen, es cierto, nuevos autores y hasta iniciativas colectivas como las que podemos reconocer en "la Bohemia del Averno" o "la nueva narrativa oriental" (véase infra), pero, en general, no encontraremos nada estrictamente programático o generacional. ${ }^{1}$ En contraste, sin fecha ni lugar precisos, la última década ofrece algo así como "cristalizaciones" de procesos, digamos, previos: líneas diversas, tanto en la narrativa como en la poesía, muestran ahora formas de conjunto, que no habríamos sido capaces de discernir previamente. En general, ese hecho se lee bastante bien (i) bajo el marco de la más explícita diversidad cultural que motiva - hoy en día - muchos de los discursos, entre ellos el literario, de esta "formación social abigarrada" (Zavaleta Mercado); y (ii) gracias a la creciente capacidad de desplazamiento - fruto de una menor dependencia de la 'necesidad referencial'- que ha logrado el lenguaje literario.

Hablé de "cristalizaciones", muy consciente de su valor analógico, aunque, pese a todo, quisiera que se las considere como descripciones de hecho, de modo que los tratamientos puntuales se entiendan, pues, como elementos que contribuyen a articular o explicitar procesos. Esta muletilla nos ayudará, espero, a no perdernos en una mera enumeración. Desde ya, el lector sabe que éste es sólo un diseño; sólo espero que, pese a sus altibajos, le permita un acercamiento hacia la actual literatura boliviana. A continuación, veamos, pues, primero la poesía y, luego, la narrativa.

\section{El ARCHIPIÉLAGO POÉTICO}

Oscar Cerruto solía atribuir a José Eduardo Guerra (1893-1943) los orígenes de la poesía boliviana postmodernista o de vanguardia. Reconocía ahí un proyecto y una

\footnotetext{
${ }^{1}$ El último 'movimiento' sería el de la "segunda Generación de 'Gesta Bárbara”, de impulso surrealista, que se difundió por los 50-60. Muchos de sus autores no han cesado de producir, aunque, como en el caso de Julio de la Vega (Matías, el apóstol suplente, 1971; Cantango por dentro, 1986) o Yolanda Bedregal (Bajo el oscuro sol, 1971), tienden ahora más a la prosa que al verso.
} 
experiencia que, a la larga, serían muy, muy cerrutianos: el silencio o soledad del lenguaje poético como acto crítico ante el mundo. Ese, en grueso, sería su más evidente aporte a la constitución del actual panorama poético en Bolivia. Más aún, Cerruto inscribe ese parámetro con tales exigencias de rigor y precisión que, a partir de él, como diría Bourdieu (Les règles de l'art 1992), la excelencia formal es parte estricta del mercado poético bolivianoy, sin ese habitus, ya no se va muy lejos. En su caso es como si la perfección formal de los poemas condicionara la posible dimensión crítica. Esta explicita, por un lado, los límites del discurso poético y, por otro, deconstruye las versiones y perversiones del poder estatal: "Una mano en el teclado/ y la otra/ en los dientes mordida" (Reverso de la transparencia [1975], en Poesia [1985], edición preparada por Pedro Shimose). Si, además, tenemos en cuenta los alcances de su producción en prosa, la obra de Cerruto es un excelente "momento crítico" de la literatura boliviana contemporánea -una de esas "condiciones límite" que Chomsky habría escogido para examinar problemas de sistema.

Este marco de rigor y precisión no es, quisiera destacar, causal. Pienso que, por ejemplo, el notable y mesurado Ahora que es entonces (1992) de Antonio Terán Cavero, aunque en contraste con su desarrollo (personal) al interior del surrealismo de la "Segunda Generación de 'Gesta Bárbara"', se lee en ese marco; pero no es ciertamente 'cerrutiano'. Análogamente, jóvenes poetas como Leonardo García (Discurso de tu imagen y $t u$ presencia, 1982; Río subterráneo, 1984), Rubén Vargas (Señal del cuerpo, 1986), Gustavo Soto (De la memoria y el retorno, 1988), Hugo Rodas (Palabras de una vez, 1993), quienes frecuentan el verso medido, preciso, poco o nada metafórico ... no son discípulos de Cerruto -aunque, como Rodas, sí le dediquen un poema. El aporte del autor de "Altiplano" a la literatura boliviana es, reitero, un habitus de rigor, no un estilo ni una 'cosmovisión'.

A este rigor y distancia críticos de Cerruto se añade, en el marco de la actual poesía boliviana, la quizá más evidente producción de un "mundo propio:" se trata de la obra de Jaime Sáenz. Su lenguaje es también prácticamente autónomo y, al principio -como en El escalpelo (1976), por ejemplo-hasta exageradamente. Siempre en su lenguaje, ninguna rareza le es ajena y desconoce la mesura: el oximoron fundido en problemas de analogía ("yo = tú = no yo") es, por ejemplo, uno de sus instrumentos más utilizados. Un "sol negro" es su horizonte de referencia y, entendiendo que la plenitud se basta sola, como en una mística negativa, prefiere frecuentar las distorsiones de la finitud como, entre otras, las del alcohol y la noche. Allí lo espera el "júbilo" --es su término- suma de éxtasis y horror. El acto poético consiste en buscar el júbilo: enfrentar el horror para alcanzar el éxtasis, en "recorrer la distancia" que los separa, aunque, a la larga, son una sola y misma cosa ("No sé que tendrá que ver el vivir con la Vida / Vida y Muerte son una misma cosa"). A partir de Recorrer esta distancia (1974) hasta La noche (1984), la poesía de Sáenz alcanza la intensidad que la caracteriza.

Cerruto y Sáenz suponen largos procesos de escritura. En contraste, el único libro de Edmundo Camargo, Del tiempo de la muerte (1969), editado póstumamente gracias a Jorge Suárez, es sólo un momento; pero uno muy intenso, que, con el correr de los años, se ha convertido en referencia ineludible en la actual poesía boliviana. La problemática de los cuerpos, de los cuerpos que todavía 'dicen' mientras se disuelven debajo de la tierra, habría sido su obsesión y desafío. Como se sabe, las "Nominaciones de lo efímero" son harto difíciles; para muchos son simplemente imposibles. Camargo las buscó en un momento 
extremo: cuando los cuerpos enterrados, reitero, comienzan a perder sus formas. "Catedrales de la imagen" (Suárez), que se están derrumbando, son sus poemas. Estas deformación y reformación de los cuerpos, más la terca pulsión nominativa que las acompaña, marcan la poesía camarguiana. $\mathrm{Y}$, por ahí, su libro se articula muy bien con la actual producción poética boliviana. Las radicales "nominaciones de lo efímero" more Camargo son casi un leitmotiv en este nuevo discurso. ${ }^{2}$

De los poetas que examinaremos en este trabajo, Sáenz es seguramente el único cuyo discurso, muy suyo, habría sido frecuentado por otros poetas. No se trata de una 'escuela' o de un 'movimiento' literarios, se trata simplemente de la utilización de un instrumento expresivo muy apto, por otra parte, para frecuentar tanto el lado extraño (y oscuro) del mundo como sus esquivas trascendencias. En ese ámbito, la poesía de Guillermo Bedregal fue, quizá, la más directamente 'saenzeana'; con dos matices, claramente perceptibles en $L a$ palidez (1975, edición póstuma con prólogo de Sáenz, precisamente): uno, versos más medidos, y, otro, un más marcado leitmotiv amoroso. Llojeta, el mítico cementerio indígena cercano a la ciudad de La Paz, fue su "intensidad", como dirían Deleuze y Guattari. También Edgar Ávila Echazú (véase su Elegía a Jaime Sáenz, 1990), Alvaro Diez Astete y Jaime Taborga han frecuentado términos, momentos de ese lenguaje y recorrido espacios análogos; aunque, en sus últimos libros - Abismo (1988) de Diez Astete y Distancias de la tarde por Jacinto Talavera (1991) de Taborga - crecen las diferencias.

Por sus trabajos sobre Sáenz - le debemos el primer estudio sobre su obra, Estructuras de lo imaginario en la obra de Jaime Sáenz (1975), y Memoria solicitada (1989, un aunque breve muy ilustrativo ensayo biográfico- - se suele asimilar, equivocadamente, la poesía de Blanca Wiethüchter a la saenzeana. Con Silvia Mercedes Ávila, Matilde Cazasola (véase infra), Norah Zapata-Prill, Blanca Garnica, Wiethüchter supone, desde ya, una renovada perspectiva femenina en la actual poesía boliviana; una que, en su caso, se traduce en agotar identidades para encontrar diferencias significativas; su "[M]e pregunto cuántas veces aún/ tendré que ofrecer mi cuerpo/ para cambiar de nombre/ y llamarme solamente a mi/ ..." de Madera viva y árbol difunto (1982) sólo puede leerse bajo una perspectiva de genéro. Pero, más aún, en esa búsqueda ella no descuida una cuidada erótica que es también 'poética', es decir, que siempre se interroga sobre sus propias condiciones de escritura (cf., ejemplarmente, su Territorial, 1983) ni tampoco es ajena al entramado histórico y cultural en el que escribe. Aunque su contexto vital es, desde 'muy temprano', La Paz (véase "En esta ciudad detenida", Asistir al tiempo, 1975), su atención es mucho más amplia como lo demuestra su más reciente poemario: El verde no es un color (1990). En el panorama que intentamos, convendría destacar, junto a la de Matilde Cazosola, la obra de Blanca Wiethüchter pues, por un lado, nos ofrece una continuidad productiva poco frecuente en nuestra poesía femenina y, por otro, sus desafíos -desde esa perspectiva- son tan atrevidos como los más.

\footnotetext{
${ }^{2}$ Camargo es un buen ejemplo en esto de las "cristalizaciones". Lo 'leemos' muy bien en relación a las más actuales articulaciones, pero sería quizá falso recurrir a criterios de desarrollo, influencia, irradiación o cosas por el estilo. Un trabajo prácticamente ignorado en su época necesitaba, por lo visto, otro horizonte cultural para su lectura.
} 
Desde La chaskañawi (1947) de Carlos Medinaceli —digamos, pues se trata en rigor de una antigua constante-, la literatura boliviana privilegia la chichería para examinar transgresiones y desplazamientos. Los lugares de farra (bodegas, cantinas, bares, en fin, chicherías) o sus instituciones (las festividades rituales campesinas, los carnavales) son ámbitos donde, como en el shibbolet derridiano, los términos intercambian sus sentidos. La poesía, por supuesto, los frecuenta, se diría, sistemáticamente.

En las zonas marginales de La Paz se encuentran los bares de su 'bajo mundo'. Algunos de estos bares se han hecho parte de la bohemia paceña. El más célebre y frecuentado es "El Averno". Podríamos llamar poesía de "la Bohemia del Averno" a ésta generada, precisamente, en relación a esas noches - Eduardo Nogales, en su intenso y denso La nave iluminada (1990), dedica un poema a éste ya casi arquetípico recinto. Esta producción resulta ser la más cercana a la de un 'círculo' en la actualidad. Aunque cada poeta hace lo suyo, todos comparten, creo, el estímulo inicial de Humberto Quino, Jorge Campero y Germán Montaño. ${ }^{3}$ Un cierto 'urbanismo marginal' sería su más evidente signo y, a través de él, podemos ver circular las más diversas tradiciones, desde las llamadas 'universales' hasta las más locales, i.e., indígenas. Al respecto, muy, pero muy personalmente, gusto de destacar el carácter arquetípico que, con el tiempo, ha logrado en ese contexto el primer libro de Humberto Quino: Atardecer de un fauno en la Avenida Buenos Aires a las 4.30 p.m. (1978). Es común en ellos una vena anarquista, muy comprensible, por otra parte, en inscripciones enmarcadas en la 'sede de gobierno' y que prolongan y desplazan, a su manera, la vena boliviana de la poesía de protesta; como en los esfuerzos de la vanguardia ('histórica'), ese anarquismo se traduce muy frecuentemente en búsquedas de identidad (por negación, a menudo) y experimentación formal - véase, por ejemplo, las obras de Diego Torres (Dizque d'Or, 1992), Juan Carlos Quiroga (Eco de Kámara, 1992), Jorge Nogales y Fernando Llanos (ambos en Poemario, 1992), entre las más recientes.

También, en relación con esta 'Bohemia del Averno', podemos reconocer búsquedas afines en otros territorios y rencuentros en el tiempo. Los encuentros espaciales son, algunos, todavía altiplánicos como en el caso de las obras de Edwin Guzmán (Delirios, 1985) y René Antezana (El labrador insomne, 1990) o ya lejanamente orientales como en el de la joven poesía cruceña (véase la Antología provisional, 1986, comp. por Antonio Rojas). Por su parte, en ese recinto, en esa 'poética', los redescubrimientos en el tiempo adquieren el valor de símbolos: así, por ejemplo, tenemos el de la revaloración de la obra del "kolla-camba superado", Neftalí Morón de los Robles, un verdadero "cronopio", cuya poesía $-\mathrm{y}$ prosa - aunque bordea el ridículo demuestra siempre una auténtica entrega social y literaria. ${ }^{4}$ Todo ello, siempre, sin afán de doctrina sino, simplemente, como un casual encuentro ... en "El Averno".

\footnotetext{
${ }^{3}$ Las antologías Fosa común (1985, comp. por Humberto Quino) y Siesta nacional (1992, comp. por Jorge Campero y Marcela Guitérrez) ilustran muy bien las características y encuentros de esta "Bohemia del Averno" en el marco de la poesía boliviana conteomporánea.

${ }^{4}$ Difícil de leer, porque uno nunca sabe cuando reírse de la ingenuidad del texto o dejarse llevar por su transparencia, Morón de los Robles ha tenido, sin embargo, un excelente lector en Manuel Vargas, quien, desde temprano nos aproximó muy apropiadamente a esas extrañas personas y obras. La bibliografia de Morón de los Robles señalaba, en 1980, 45 título (véase su Antología poética II, comp. por el autor), donde encontramos desarrollos de este tipo: Historia de la mujer, Breve historia de la mujer, Brevísima historia de la mujer -progresiones que, dicho sea de paso, le gustaba destacar.
} 
Estos encuentros me sugieren otro que, creo, también permite ilustrar aquello de las 'cristalizaciones'. Entre otros, tres poetas bolivianos se han aproximado a la 'poesía concreta', tanto en sus lecturas, investigaciones como en sus obras: Quino Nicomédez Suárez (El poema América, 1971; Amnesis Art, 1988) y Marcelo Arduz (La tierra en uno, 1990). En principio, carecen de vínculos directos; pero los tres han estudiado hasta, diría, minuciosamente la obra de Eugen Gomringer, uno de los más influyentes poetas y teóricos de esa tendencia en Europa - y casualmente, Gomringer nació en Cachuela Esperanza, allá en los llanos orientales bolivianos.

En las referencias a la literatura boliviana hay - en general — un presupuesto 'andino' que, lastimosamente, simplifica demasiado su apreciación. Ahí, por ejemplo, no entran muy cómodos las palmeras ni el "matecito de coca" de Shimose, el "Poeta Movima" de Nicomedes Suárez, Yerubia o "E1 Urundel" de Jesús Urzagasti, la "poesía joven de Santa Cruz" o los versos pandinos de Ramón Campos, las connotaciones chapacas de Roberto Echazú (Morada del olvido, 1990), aun las 'vallunas' de Gustavo Soto o de Antonio Terán Cavero, ni pese al saludo final al Altiplano, El verde noes un color de Wiethüchter. Aunque la inercia ha sido y es andinista, hay muchas cosas más en esta poesía. El poeta que mejor permite destacar la diversidad cultural implicada en la poesía boliviana es, creo, Pedro Shimose. Y, aunque como pretexto en este párrafo he utilizado las connotaciones territoriales afines a los poetas mencionados, el lector comprenderá que no se trata, en rigor, de describir una geografía sino de discernir un aparato productivo, un espesor de sentidos que, enriqueciendo y - a menudo - desplazando la tradición andina, pone en evidencia las otras caras de esta cultura. Los 'cambas' prefieren los taquiraris a las cuecas ... pero nadie canta "Sed de amor" como doña Gladys Moreno.

Ya en Poemas para un pueblo (1968), entretejiendo textos y contextos, Shimose recorre el país dialogando con diversos poetas y sus poemas, indicando así afinidades y diferencias:

Cuando voy por el sur, Roberto Echazú me dice: 'Este país no-país'/ y nos amanecemos frente a un vaso de vino;/ regreso a Chuqisaca y Ayllón Terán me avisa que vivimos a/ 4000 metros del hambre; me voy a Cochabamba y, alli, Gonzalo Vásquez me dice: 'Este país tan solo en su agonía; tan desnudo en su altura ...; ; camino a Santa Cruz y me encuentro con Julio de la Vega,/allá, junto a las guitarras con diez buris metidos/ en la sangre.

Esta dúctil capacidad intertextual es una de las características de Shimose. Además, como quien busca el instrumento más amplio posible para la diversidad que lo motiva, desde Triludio en el exilio (1961) hata Bolero de caballeria (1985), ha experimentado con todas las formas de la poesía contemporánea. Casi como síntesis de esos esfuerzos tenemos su impecable Reflexiones maquiavélicas (1980). En esa búsqueda, una constante es su rebeldía crítica ante la injusticia social; al respecto, su Quiero escribir, pero me sale espuma (1972) con sus personae, en el sentido de Pound y a la manera de Pessoa, es ejemplar: ahí la crítica social es también la inscripción de una pluralidad de voces sociales y poéticas. La otra constante shimoseana son sus referencias a sus llanos moxitanos y a su Riberalta natal, allí, precisamente donde crecen sus palmeras y le espera su matecito de coca. La reciente edición de sus Poemas (1988) reúne todo este su trabajo. 
Shimose nos permite acercarnos también a un otro polo, muy esquivo para muchos, de esta poesía: aquel vinculado con la 'canción popular'. Una de sus canciones, el taquirari "EI sombrero de Sao", es todo un clásico en fiestas y serenatas. Obviamente, este género vive más allá de toda academia: canta y baila. Arquetípica en este sentido es la obra de Matilde Cazasola; en ella, escrituray canto alternan permanentemente sus términos - desde ya, ella es una figura maestra de la "nueva trova" boliviana. ${ }^{5}$ Por otro lado, gracias a nuevas composiciones, muchos clásicos de la poesía contemporánea (y tradicional) se transforman ahora en canciones populares. Así, por ejemplo, Eduardo Farfán musicalizó poemas de Oscar Alfaro y Octavio Campero Echazú; Jenny Cárdenas ha integrado versos mineros de Vallejo en esta 'tradición'; Jesús Durán ha hecho una ya inevitable cueca de un poema de Saenz: "Si te encuentras con la Flora/ acordándose de mí/ no le digas que la quiero/ en un rincón del olvido/ no le digas que la espero." En esta vena, el esfuerzo más sistemático es, sin duda, Memoria del destino (1991), la antología musical de la poesía boliviana compuesta por Juan Carlos Orihuela y Oscar García, ambos también poetas. Al la inversa si se quiere (del canto a la poesía), en su Serenata (1991), Jorge Suárez, quien gusta explorar más bien formas clásicas (véase Sonetos con infinito, 1991), ha recogido formas de la canción popular boliviana para armar sus nuevos poemas. Estos caminos complican los alcances, haceres y (aún) comprensión de la poesía boliviana; pero, una vez más, ponen en evidencia el complejo entramado discursivo, cultural, donde éste sucede. Al respecto, hay un ejemplo que me gusta destacar.

Por el lado andino, digamos, tenemos el preciso El danzante y la muerte (1983) de Fernando Rosso. Este poema se basa en la tradición altiplánica según la cual alguien que ha sido expulsado de su comunidad puede retornar a ella si, antes, danza hasta morir. Este retorno sugiere una odisea donde la reconciliación final no mata sino, más bien, muere. Esta misma tradición, claro que en un código muy distinto, la encontramos en la trama de La nación clandestina, la última película de Jorge Sanjinés. Dejo al lector que imagine las implicaciones connotadas en ese nudo y, sobre todo, bajo el marco de la 'lógica del retorno'.

En poesía - y en literatura, en general- la articulación de este entretejido discursivo no iría más allá del experimento verbal como búsqueda de nuevas formas de expresión en el sentido vanguardista (caduco) de "hay una nueva realidad - la modernidad - que requiere otros lenguajes"- si, paralelamente, la palabra poética misma no hubiera sido objeto de un nuevo tipo de atención, todos los poetas mencionados, de una u otra manera, no usan su instrumento sin antes, o al mismo tiempo, haberlo valorado. Pero, quizá, la mirada más minuciosa y explícita al respecto es la de Eduardo Mitre. Entre los objetos y acontecimientos del mundo encuentra, evidentemente, también al lenguaje y lo examina casi sin cesar. Ya en Ferviente humo (1978), por ejemplo, Mitre sabe que no puede asumir otras voces sin cederles la palabra y, por ahí, cada poema supone también una distinta persona poética; cuando busca frágiles nominaciones de cosas o seres, de esas que la oralidad tiende a arrastrar en su ritmo, frecuentemente deja que el ideograma, el silencio o

${ }^{5}$ La obra de Casazola incluye libros de poemas como Los cuerpos (1976) o Y siguen los caminos (1990), entre otros; de prosa poética como sus Estampas, meditaciones, cánticos (1990); ograbaciones musicales como De regreso (1984) o Cuatro estancias poético-musicales (1988)—esta última es una antología de sus canciones. 
la página blanca digan lo suyo (véase Morada, 1975, o Mirabilia, 1979); su erótica —una de las más delicadas - se entiende mejor como parte de su trato (amoroso) del lenguaje; en su momento, sabe desplazar sus versos en otros que ya han marcado el camino; su poesía es, a menudo, un 'metalenguaje' poético. Así, también, por supuesto, construye su mundo; uno muy marcado por el nomadismo y la nostalgia. Aunque habría que irradiar, en su caso, el concepto hasta la minuciosidad del haiku, creo que la elegía es el género que mejor describe la poesía de Mitre - y, en ese ámbito, los poemas "Yaba Alberto" y "El peregrino y la ausencia" (en La luz del regreso, 1990) son dos perfectos ejemplos de sus logros. La elegía, como se sabe, se enfrenta necesariamente con nominaciones que no pueden dejar de pensar en los límites y posibilidades del lenguaje. En manos de Mitre, pues, las palabras no dicen si antes no ha sido encontrado su lugar entre los acontecimientos, seres y objetos del mundo.

Estos serían algunos rasgos, ojalá pertinentes, de la actual poesía boliviana. El diseño no es necesariamente cronológico — de ahí la noción de 'archipiélago' en el subtítuloaunque he querido inclinar la balanza hacia la última década. No hay mayores relaciones causales, aunque, como en el caso de la poesía de la "Bohemia de Averno" o en la persecución de los temas saenzeanos, no faltan afinidades. Hay, sobre todo, encuentros. Si tuviera que proponer una ecuación para ese esquivo objeto, creo que le daría esta forma: bajo crecientes exigencias de rigor y precisión, desde una 'perspectiva multipolar' (Rodríguez Casas) sobre los alcances y límites del lenguaje, asumiendo la diversidad cultural no como simple referencia sino como condición de sentido, frecuentando ámbitos discursivos de transgresióny permanente desplazamiento, insistiendo tercamente en intensas nominaciones de lo efïmero, la poesía boliviana de las últimas décadas es ahora una muy sugerente, lúcida, intensa y creo que, algún día, comenzaremos también a entenderla como un atrevido acto de conocimiento. Pasemos ahora a examinar la narrativa.

\section{HaCIA EL FIN DE LOS LÍMITES}

En las décadas de los 70 y 80 , la narrativa boliviana evidencia mayor riqueza instrumental y una creciente libertad y diversidad temáticas. Estos hechos se notan fácilmente en contraste con el tradicional 'realismo' boliviano. Éste no sólo era, digamos, referencial, representativo, sino también marcadamente 'reactivo': sucedían los hechos, se producía el texto y, salvo notables excepciones, era fundamentalmente monológico: casi dominado por la ecuación autor $=$ narrador. Teniendo en mente ese contraste, a continuación y siguiendo un tenue modelo de 'complejidad creciente' — no estrictamente cronológicotrataré, pues, de describir este más variado panorama de la nueva narrativa boliviana" (Rivera-Rodas).

El modelo que utilizo tiene tres facetas: una, señalar algunas maneras como los hechos referenciales, casi a la inversa del 'realismo tradicional', se subordinan más y más a la trama del relato; otra, que en la nueva narrativa el examen de las situaciones límites, extremas, marginales tiende a producir objetos y sujetos "grotescos" (Sanjinés) de ficción, que ponen en entredicho muchas dimensiones del entramado discursivo boliviano; $y$, la tercera, que al ignorar fronteras como las que señala, notablemente, la oposición vida/muerte el imaginario de esta narrativa se ha hecho ciertamente más rico y dúctil, pues le permite circular más libremente, como diría un antrolopólogo, por sus diversos imaginarios. Veamos. 
Una muy sugerente torsión en la trama de Bajo el oscuro sol (1970) de Yolanda Bedregal permite indicar cómo, en la nueva narrativa, las referencias contextuales se subordinan más y más a la trama del relato. En una de las tantas 'revoluciones' (i.e., 'golpes de estado') del país, una estudiante muere víctima inocente de una bala perdida. Desde lejos, este primer momento de la novela nos sitúa en una arquetípica trama realista, con su ontología y todo: los individuos son, finalmente, víctimas -inocentes (o culpables) - de los más trascendentes conflictos sociales. Verónica Loreto es la víctima casual de la bala perdida. Pero, posteriormente, su profesor, el Dr. Gabriño, quizá enamorado de ella, decide investigar su vida y descubre que Verónica era parte de una larga cadena incestuosa, una cadena que ya debía nomás llegar a su fin. De esta manera, la novela nos da a entender que la accidental bala perdida era, en rigor, el instrumento - harto motivado- que castigaba esos incestos. Bajo esta torsión narrativa, los elementos contextuales ('revolución' = bala perdida) se hallan, pues, subordinados a la trama del relato (cadena incestuosa $=$ muerte de Verónica).

Un creciente uso de este tipo de torsiones resulta pues, en relatos más autónomos. En el diseño anterior, jugando con Freud y Barthes, diríamos que el "principio del placer del texto" gobierna el "principio de realidad de la representación". Aquí habría que tener en cuenta todo el complejo técnico e instrumental, fruto de la irradiación del "boom" de la novela latinoamericana, que se incorpora en esta nueva narrativa. Es éste el que facilita las torsiones. La utilización de ese instrumental en esta narrativa tuvo, sobre todo en los 70 , un efecto, digamos, negativo: la riqueza técnica se acompañaba a menudo de meros "vacíos temáticos". Tal vez por exceso de experimento técnico, varios textos como se pierden o carecen de tramas y, finalmente, hasta de relato. Se dice poco, aunque se dice en diversidad. Como éste es, creo, un 'juicio de valor', me abstengo de mencionar obras y autores. El lector los reconocerá fácilmente - aunque, en algunos casos, donde el experimento ha sido muy rico, muy sugerente, como en El apocalipsis de Antón (1972) de Von Vacano, uno lamente la carencia de trama articuladora.

Creo que este hecho puede ser vinculado con otro, solución, a su manera, del problema anterior: el creciente recurso al tema histórico $-\mathrm{y}$, asimismo, un acercamiento a la vida cotidiana. Aquí estaríamos ante una suerte de 'realismo' técnicamente enriquecido. Este 'neorrealismo' y no persigue tanto los sucesos inmediatos y comienza a recorrer bastante libre y, a veces, hasta imaginativo, la historia boliviana. ${ }^{6}$ Néstor Taboada Terán, por ejemplo, ya a partir de Signo escalonado (1975) y, notablemente, con su Manchaypuytu (1977), ha emprendido una tarea que, a la larga, tiene en mente todo un panorama de los períodos mayores de la historia boliviana - su última novela (Ollantay, en manuscrito) diseñaría la época precolombina, antesala de la colonial tratada en Manchaypuytu. Joaquín

\footnotetext{
${ }^{6}$ En los 70 encontramos todavía la inercia de la 'novela de la guerrilla' motivada, en estos lares, por la muerte de Che Guevarra en La Higuera. Obras como Los fundadores del alba (1969) de Renato Prada, Ñancahuazú-Sueños (1969) de Jesús Lara, Matías, el apóstol suplente (1971) de Julio de la Vega, La oscuridad radiante (1976) de Oscar Uzín, Tiempo desesperado (1978) de José Fellman, por ejemplo, persiguieron los hechos y efectos de ese suceso. Actualmente, quizá comienza a diseñarse una especie de 'narrativa de la coca-cocaína' (véase, entre otros, Torbellino de horas (1984) de Olga Bruzone de Bloch y Mariposa blanca (1990) de Tito Guitiérrez).
} 
Aguirre Lavayén ya tematizó la Conquista del Oriente boliviano en Más allá del horizonte (1951) y las motivaciones de la Guerra del Pacífico en Guano maldito (1976). Más inmediato, Enrique Rocha Monroy ha diseñado, por ejemplo, los últimos días de Villarroel en El rostro de la furia (1979) y, caricaturescamente, la vida de Barrientos en Medio siglo de milagros (1979). Esta última figura, como la de Melgarejo, tiene especial atractivo por estos lares y también ha motivado El mejor del convento (1991) de Mario Lara Claros; el periodo barrientista también se reconoce en Los otros (1992) de Luis Antonio Mendoza.? Aunque, noto, las figuras políticas relativamente inmediatas suelen ser las más frecuentadas, este recurso a la temática histórica quizá colabora a conformar (en esta narrativa) una especie de "distancia ante los hechos", la que en los tratamientos más complejos (véase infra) se articula con la puesta en evidencia de las condiciones de escritura de los cuentos o novelas.

Otra cara de este neorrealismo tiende al diseño de la vida cotidiana en el campo y la ciudad. La vida pueblerina, campesina, es la más frecuentada, como podemos leer en las obras de Ernesto Contreras (El primo Juan, 1990), Giancarla de Quiroga (La flor de "La Candelaria", 1990), H. C. F. Mansilla (Opandamoiral, 1992), Enrique Rocha Monroy (Presagio para dos muertes, 1992); muchos de los cuentos de la "nueva narrativa oriental" (véase infra) también frecuentan ese tipo de temas. En este ámbito, me gusta destacar la delicadezay precisión narrativas de Manuel Vargas, aquellas, por ejemplo, que encontramos en sus Estampas (1988) o, en la serie de "La novela [vallegrandiana] de Fermín" (Rastrojos, 1984; Callejones, 1990). Aquí y allá, la macrohistoria suele entreverarse con las historias y costumbres locales o regionales; así, por ejemplo, lo cotidiano y lo político alternan constantemente en los cuentos de Homero Carvalho (Biografia de un otoño, 1983; Seres, 1991). Un otro polo de esta temática es el de la vida cotidiana urbana; ahí, entre otros, tenemos, las obras de Adolfo Cáceres (Las víctimas, 1976), Gonzalo Lema (El País de la alegria, 1987; Anota que soy un hombre, 1990) o la última novela de Edmundo Paz Soldán (Días de papel, 1992); en La sierpe empieza en cola (1991), Gaby de Bolívar —como en su anterior Hijo de opa (1977-se ocupa de vidas marginales urbanas, ahora por el lado de la delincuencia como antes por el de la política criolla. La posible 'narrativa de la cocacocaína' tocaría de cerca este tipo de vidas marginales.

En grueso: aunque a veces la trama no anda a la altura de instrumento, es claro que este 'nuevo realismo' ya no es monológico.

Desde las iniciativas, sobre todo, de Renato Prada, uno de los fundadores ciertamente de la "nueva narrativa boliviana", el 'autor' ha cedido su espacio a las personae narrativas. Desde muy temprano, los cuentos y novelas de Prada eran ya un caledoscopio de voces: la dialéctica entre los 'unos' y los 'otros' es una constante en su obra y, por ahí, dicen de diferente manera; ${ }^{8}$ también Manuel Vargas ha armado su 'mural' narrativo aprovechando

\footnotetext{
7 'Desde lejos', en El laberinto de las desilusiones (1983), H. C. F. Mansilla ha narrado los avatares del célebre "Mayo '68" en Alemania Federal —desde el punto de vista, distanciado e irónico, de un estudiante boliviano quien, de súbito, se encuentra en ese torbellino ideológico.

${ }^{8}$ Desde sus primeros cuentos (Argal, 1968) hasta su última novela Pocos después humo (1989), la obra de Prada cubre un amplio espectro tanto en la 'forma' como en el 'contenido'; pero, como hilo conductor, tendríamos la búsqueda de sentido para el individuo en medio de la enajenación social. Su obra, dicho sea de paso, se completa con sus múltiples aportes a la teoría literaria y al estudio de
} 
cuidadosamente diversas perspectivas de narración. Muchos de los cuentos de Jorge Suárez, recogidos en Memorias del cuarto mundo (1985), son voces que rememoran. Un caso extremo es - quizá porque el personaje lo permite - el de las Memorias de Holofernes (1992) de Félix Del Granado, donde el caballo de Melgarejo ('Holofernes', precisamente) recuerda a su amo. Los ejemplos pueden ser ampliamente multiplicados. Aquí, quizá, incluyendo ciertamente a Manuel Vargas, Paz Padilla Osinaga ( Nel umbral, 1986; El gemido del huracán, 1991) y —-parcialmente - a Jorge Suárez, podríamos destacar esa especie de polifonía de voces que la "nueva narrativa oriental" (véase Taller del cuento nuevo, 1986, comp. por Jorge Suárez) ha introducido durante estas décadas en la literatura boliviana. Por estos caminos, gracias a una mayor pluralidad de voces y perspectivas, es obvio que, en general, la narrativa boliviana no sólo utiliza sino también construye sus niveles de narración.

Antes de los 70, sin embargo, esa diversidad dialógica no llegaba frecuentemente al entrecruce entre narración y relato. Sólo Tirinea (1969) de Jesús Urzagasti habría explorado ese ámbito, cuando Fielko el narrador deja que EI Viejo, uno de los personajes explícitamente armados en el relato, se haga cargo del fin de la novela mientras Fielko retorna a la vida. Luego, sí, encontramos más a menudo la utilización de este recurso que, entre otras cosas, pone en evidencia el acto de escritura. Arturo Von Vacano, al final del aniquilante sino que arrincona al narrador de Morder el silencio (1980), asume la escritura como el último resquicio de sentido. En la misma vena, en la ícara, sensual y ágil Jonás y la ballena rosada (1990) de José Wolfango Montes Vannuci, Jonás confiesa al lector que lo ha hecho cómplice de sus agitados amores con Julia porque sólo narrándolos podía, en cierta forma, revivirlos. Otra vez marzo (1990), novela póstuma de Marcelo Quiroga Santa Cruz, alterna diversos niveles de recuerdos - relativos a la vida de José, ex-capitán — de modo que el último, o sea, el 'presente' (el 'ahora') de la narración lee a su manera a los demás y, así, los valora mientras se relatan. También, en Días de papel, Paz Soldán problematiza la trama con una interrogante sobre el sentido del acto de narrar, de escribir.

En estos casos, aunque ya es evidente el aprovechamiento de los entrecruces de narración y relato, todavía los tenemos en función del climax del relato. Hay otros textos donde ese dialogismo es, digamos, permanente: El otro gallo (1984) de Jorge Suárez, En el país del silencio (1990) de Jesús Urzagasti estarían entre ellos. Veamos, brevemente, algunos rasgos de estos dos textos, que, personalmente, aprecio mucho.

Desde ya, El otro gallo es un sistema de relatos. Los cuentos, leyendas y aventuras ficticias con (y contra) los carabineros, que narra Luis Padilla Sibauti desde su imaginario "Bandido de la Sierra Negra", se acompañan permanentemente con las intervenciones de una otra narración, la que diseña el entorno, arma las vidas de los personajes y, además, teje la intriga de la 'muerte' del primer narrador; así, no sólo el relato, como es tradicional, vive en las tensiones entre realidad y ficción sino, también, se problematizan los diversos niveles narrativos. Felizmente, dicho sea de paso, la 'muerte' del narrador imaginario era sólo un otro (pícaro) cuento al interior del cuento, de modo que, pese a los carabineros, "El Bandido de la Sierra Negra" puede seguir contando sus ficciones.

la literatura latinoamericana, como su reciente Los sentidos del símbolo (1992) permite claramente ilustrar. 
En el país del silencio desarrolla tres niveles de relato. Cada uno de ellos construye un personaje, sobre todo a través de recuerdos u olvidos, el que, a su vezes, alternativamente, narrador en los otros dos niveles. Así se arman tres 'mundos': uno más marcado por el olvido, relativo a la vida provincial del Chaco boliviano; otro, rememorativo, donde se persigue la vida de Jursafú y su tránsito del 'campo' a la 'ciudad' (también: el 'mundo'); y el tercero, de permanente presencia, que recoge el único día donde, en realidad, sucedería la novela - este tercer nivel es el que más explícita y constantemente pone en evidencia el acto de escritura. Como intertexto común a los tres niveles, En el país del silencio incluye una serie de relatos prácticamente autónomos, cuyas diversas connotaciones parecen recorrer toda la novela y donde, entre otros, se encuentra el perfecto dedicado a "El urundel"- - texto que, a mi entender, es el nudo clave de ese entramado textual.

Hasta aquí, recurriendo, primero, a una sugerente torsión en la trama de Bajo el oscuro sol de Bedregal y diseñando, luego, algunas transformaciones, tensiones y enriquecimientos instrumentales, hemos examinado una primera faceta de la nueva narrativa boliviana, aquélla que permite destacar, sobre todo, sus 'distancias' con las tradiciones representativas del relato. A continuación, veamos, pues, una segunda faceta, la relativa al tratamiento de "lo grotesco".

De partida, señalemos que el concepto es de Javier Sanjinés; viene de su El grotesco social en la literatura boliviana contemporánea (La Paz, ILDIS-FBHN, 1992) y nos permite acercarnos aún más hacia las fronteras y límites que anda persiguiendo esta narrativa, allí donde las formas comienzan, precisamente, a devenir informes, es decir, grotescas. Como hicimos con la ayuda de Bajo el oscuro sol, un breve examen argumental nos servirá para entrar al tema. En este caso, recurramos a La tumba infecunda (1985) de René Bascopé Aspiazu (1954-1984).

Desde su infancia hasta su vejez y, aun, su merte, si tenemos en cuenta que no llegará a ocupar su ya adquirida tumba, Constantino Belmonte no hace otra cosa que pasar de una a otras situaciones marginales. Desde que descubre al viejo brujo Bengurias en las afueras de Irupana, desde sus amores con la repudiada Genoveva, en su anónimo trabajo burocrático, hasta su retirada vida de jubilado en uno de los conventillos paceños, pasando por su vida de aparapita y por su trabajo en los burdeles de Caiconi, primero, y, luego, de Conde Huyo, Constantino Belmonte, el personaje principal de La tumba infecunda, ocupa, pues, todas las posibilidades de un destino marginal. Nunca, se diría, está en 'alguna parte'. En esta novela, la marginalidad representada es tan extrema que la encontramos en los detalles de casi cada (toda) escena y, aun, expresión.

Desde esta perspectiva, ese ámbito temático sería, en rigor, un ámbito discursivo. Desde ya, aquí hay que tener en cuenta todos los factores mencionados al examinar la primera faceta, pero hay más. No es tan arbitrario -o mero efecto, en Bolivia, de las tendencias narrativas contemporáneas - que se frecuenten estas marginalidades ni que se abandone la vena 'realista' de los sucesos sociohistóricos inmediatos. Lo que pasa, nos diría Sanjinés, es que la discursividad propia al Estado del 52, muy afín a la verticalidad dictatorial que acabó por caracterizarlo - y acabarlo- era también un horizonte de sentido. Es obvio que, perdido ese horizonte, se busquen otros, como en lo social, desde 1978, se anda buscando darle forma a la democracia. Pero, esos horizontes discursivos todavía no están claros. Mientras tanto, entoces, se frecuentan marginalidades, extremos, deformaciones, 
en fin, varias gamas de "lo grotesco". ${ }^{9}$ Ese "grotesco" tiene dos filos: uno de directo absurdo y sin sentido, como que eco del acabóse del horizonte discursivo anterior; $y$ otro de 'búsqueda', digamos, donde lo informe de las formas, valga la expresión, puede que puede que, reitero - construya o anuncie un renovado horizonte, que todavía no alcanzamos a comprender. La nueva narrativa - como la poesía también; aquí es imposible aislar géneros-también andaría por ahí.

Esta informalidad tiene mucho, creo, del 'saco del aparapita' descrito por Sáenz en Felipe Delgado (1979). ${ }^{10}$ Este saco está hecho de remiendos, de todas las telas, desde pedazos de terciopelo hasta fragmentos de yute, de todos los colores, cosidos con cualquier hilo o pita, hasta alambres. Arturo Borda, en su "El yatiri" pintó uno semejante. con el tiempo, los remiendos han reemplazado totalmente el saco original y, sin embargo, de alguna manera, paso a paso, ha conservado su forma. todo un bricolage levistraussiano, se diría; pero, lo que aquí interesa destacar es que, pese a la forma 'original', la materialidad diversa y fragmentaria es la que hace la particularidad del 'saco del aparapita' y, sólo a partir de ella se 'adivina' el posible original. Análogamente, en "lo grotesco" son los multiples discursos extrañamente articulados —y seguramente también a retazos- - los que sugieren posibles originales 'detrás' de sus informes materialidades. Por ahí andaría lo que Sanjinés denomina (ver abajo) "grostesco jubiloso": un horror que, a su manera, revela plenitudes.

En este ámbito, hay dos hilos harto tradicionales en la narrativa boliviana que, bajo estas circunstancias, habrían sido profundamente modificados: uno, la 'literatura indigenista' y, otro, la literatura minera. En el primer caso, hay toda una situación discursiva y, en el segundo, una innegable reformulación referencial.

En las décadas que examinamos, no hay prácticamente una narrativa indigenista en Bolivia. Cierto, hay textos que tocan temas campesinos, pero no hay esa narrativa crítica y revindicativa que caracterizó al tema. No es fácil discernir el hecho, de modo que, señalemos un par de hipótesis. Por un lado, creemos que la creciente autoconciencia campesina e indigenista, claramente manifestada en la conformación de la Central Sindical Única de Trabajadores Campesinos de Bolivia (CSUTCB) y del movimiento katarista que la acompañó, conforma un discurso 'propio', que puede casi prescindir de mediaciones, en este caso, literarias; por otro lado, otros discursos serían más aptos para las actuales circunstancias y, ahí, la irradiación propia al cine de Jorge Sanjinés - con sus matices y transformaciones internas- es, creo, un muy sugerente hecho y ejemplo (véase supra, la mencion a La nación clandestina). Hay otras posibilidades explicativas; quedémonos con estas dos: en todo caso, es difícil encontrar una 'narrativa indigenista' en estos días en Bolivia.

\footnotetext{
${ }^{9}$ Los argentinos me entenderán bien después de la notable Una sombra ya pronto serás (1991) de Osvaldo Soriano. Para no ser tan arbitrario en este paralelo, señalo que, en esta novela donde acabaría el mito del Sur argentino — su, quizá, horizonte de sentido—, la mayoría de los personajes migran ... hacia Bolivia.

${ }^{10}$ La obra en prosa de Sáenz incluye Imágenes paceñas (1979), Los cuartos (1985); y las ediciones póstumas de Vidas y muertes (1986), La piedra imán (1989) y Los papels de Narciso Lima Achá (1991).
} 
En lo que toca a la narrativa minera, a partir de los años $70 \mathrm{y}$, sobre todo, en la obra de René Poppe podemos observar una notable transformación referencial. Difícilmente, la anterior narrativa minera entraba al 'interior mina'; era horizontal, de superficie, muy articulada con las tensiones, conflictos, horrores, que enfrentaban la clase minera con los aparatos del Estado. En Poppe, esos enfrentamientos no desaparecen, pero, primero, el relato baja a a la mina: toma la 'aula', desciende y, allí, sucede un otro mundo y un muy diferente tipo de intersubjetividad social, uno muy cercano al de las tradiciones y los rituales indígenas. Ahí está, por ejemplo, 'El Tío', ese Señor fálico del interior mina, al que siempre hay que ofrecer un cigarrillo y un puñado de coca; también están los compañeros muertos, los que ahora son las 'ánimas' que protegen a los mineros en los terribles socavones; en fin, un mundo subterráneo - con todas las connotaciones del término: véase, Camargo o Sáenz, ya mencionados - entre terrible y mágico, y, sin embargo, subrayo, absolutamente cotidiano. Poppe, a través de obras como los Cuentos mineros (1985), El paraje del Tio y otros relatos mineros (1985) y, notablemente, La khola (1975) es el que más explícitamente ha producido esta transformación en la narrativa minera boliviana.

Quizá lo que sigue —el examen de la tercera faceta del modelo que nos guía - es también un corolario de lo anterior. En el esfuerzo narrativo por romper barreras de significación y sentido podemos también reconocer la construcción de formas grotescas. En la frontera de los 60, Quiroga Santa Cruz con su novela Los deshabitados (1957) y Cerruto con sus cuentos de Cerco de penumbras ([1958]) prefiguraron mucho de la "nueva narrativa boliviana". Si Quiroga Santa Cruz introdujo las problemáticas de la cotidianeidad y la subjetividad en una narrativa más inclinada al tratamiento de los problemas macrosociales, Cerruto es el primero que, sistemáticamente, lleva esta narrativa hacia los temas y problemas de los sueños y pesadillas, locuras y retornos de la muerte. Es un sistema de pasajes, y por ahí se rompen o problematizan criterios vigentes. Por ese camino la nueva narrativa boliviana explora, pues, otros niveles de significación y quizá de sentido. La oposición vida/ muerte es una de las más frecuentadas.

Al principio reconocemos un obstáculo: esas barreras no son nada fáciles de vencer. En su Manchaypuytu, recurriendo a la leyenda colonial, Taboada Terán pone ese hecho en evidencia. A su retorno de un viaje a Lima, el padre Antonio descubre que su amada María Cusilimay ha muerto. Desesperado, la desentierra y por todos los medios trata de revivirla. Fracasa. Finalmente, toma un hueso de la víctima, talla en éste una quena y luego, inclinado sobre un gran puytu (cántaro), enajenado, pasa sus días ejecutando el inmortal yaraví —el que da nombre a la leyenda y al libro. Esta 'suplencia' del arte, del yaraví, ante las imposibilidades en la realidad es, desde siempre, una de las posibles funciones del hecho estético; pero, en lo que nos ocupa, para que ese hecho estético vaya más allá de la saudade, de la suplencia, es además necesario que las entidades ficticias logren no una 'existencia' -ya la tienen, a su manera, en su ámbito discursivo - sino un sentido capaz de alternar con otros. Quizá desde siempre se narra así, pero teóricos como Pierce (sentido = significación + interpretante) y narradores de la talla de Borges y Rulfo nos han ayudado a entender los más ricos alcances de esa operación. En Felipe Delgado (1979) de Sáenz, el acto aparatita de 'sacarse el cuerpo' indica un paso en ese sentido y, por ahí, la narrativa boliviana se enfrentaría más libre ante la muerte. 
En Felipe Delgado, el sentido de la vida sería algo muy análogo al 'sacarse el cuerpo' de los aparapitas. Cuando el cargador aymara sabe que su tiempo le ha llegado, trabaja ininterrumpidamente, junta el dinero que necesita y, luego, se encierra en una bodega bebiendo alcohol hasta morir, hasta 'sacarse el cuerpo'. Después, su cuerpo es echado a la calle. Ritualmente, sus compañeros recogen los objetos que también les pertenecen. El cuerpo va a parar a la morgue o quién sabe dónde, pero ya no importa: ahora es el espíritu protector de esa bodega y sus compañeros así lo saben - en la narrativa minera de interior mina, el mismo sentido se atribuye a los compañeros que mueren en los socavones; la tradición del danzante y la muerte anda por análogos caminos. Este ya sería un "grotesco jubiloso", como diría Sanjinés al respecto. Pero, hay otras facetas más.

Teniendo en mente el Run run de la calavera (1988) de Ramón Rocha Monroy, podemos tomar casi a la letra eso de (véase arriba): "se enfrentaría más libre ante la muerte" y además, añadirle una dimensión lúdica; como cuando recordamos que en el texto, para poder recuperar su "guadañita", la Muerte - ahora convertida en la coqueta "Ñatita"- debe jugar una decisiva partida de rayuela ${ }^{11}$ con Valois, el galán de Pocona. Ahí, en noviembre, durante las fiestas de Todos Santos y Difuntos, vivos, muertos, sacros y profanos - y por supuesto la Muerte = "Ñatita"- comparten una dionisíaca francachela, muy afin a las tradiciones rituales de los valles cochabambinos, donde ciertamente es ya inútil preguntarse sobre la oposición vida/muerte. Con mucho humor, presente no sólo en las escenas sino a cada paso de su pícaro lenguaje narrativo, Rocha Monroy nos ofrece todo un retrato de Pocona y sus personajes, enriquecidos con la posibilidad de entreverar diversos tiempos, diversas épocas - entre ellas, la de la oligarquía terrateniente-gracias a esta resurrección de los muertos. Obviamente, de acuerdo a la función de estos rituales, la fiesta llega a su fin; es entonces cuando la Muerte juega rayuela, antes de retornar a sus 'labores', como los muertos a sus tumbas, los vivos a su cotidianeidad y los santos a sus hornacinas en el templo. El texto, como el ritual, ha permitido, sin embargo, una prolongada convivencia.

Desde otra perspectiva, en De la ventana al parque (1992) de Jesús Urzagasti también se 'vence' a la muerte. El texto tiene por referencia una serie de personas, ya fallecidas, que nollegaron a concocerse. En la siempre poética prosa de Urzagasti, la implícita rememoración de estas personas se transforma cuando el texto examina, como nudo de su trama, las amistades que hubieran podido establecer si se hubieran conocido, encontrado, en vida. Así, el texto se convierte en un ámbito de mediaciones: los desconocidos se conocen, los muertos se encuentran, dialogan, se diría, comparten afinidades; también, por supuesto, muestran sus diferencias y discrepancias. En todos los casos, Urzagasti sabe comunicarnos aquello que Barthes llamaría el punctum, es decir, la característica fundamental de las personas; características que, precisamente, a través de afinidades y diferencias, le permiten articular las posibles amistades. Además, la narración nos ofrece, aquí y allá, una serie de breves reflexiones sobre el tema de la muerte, las que, a la larga, arman un muy apropiado horizonte para las amistades que suceden en el relato. De la ventana al parque permite, pues, el nacimiento de nuevas amistades ... más allá de la muerte.

\footnotetext{
11 "Rayuela" en el sentido valluno del juego, no cortaziano: en un adobe, a distancias variables según la pericia de los rivales, hay que embocar (dos) monedas en un hueco.
} 
Hemos llegado al final de este breve recorrido por la nueva narrativa boliviana. Con la ayuda de un harto arbitrario modelo, hemos examinado tres de sus facetas: sus distancias ante la representación 'realista', su tratamiento de "lo grotesco" y, finalmente, sus inscripciones de sentido. Por supuesto, las obras mencionadas existen independientemente del modelo y, a menudo, implican las tres facetas que nos guían.

\section{CONCLUSIONES PARCIALES}

Sólo por razones expositivas he aislado poesía de narrativa. Desde ya, como habrá notado el lector, varios autores frecuentan ambos géneros y, por ahí, sería muy fácil establecer los puentes; los que, más un criterio (rhizomático) de irradiación, por ejemplo, harían de este panorama quizá algo así como un entrecruce de discursos literarios. Pero, volviendo un segundo al modelo utilizado para tratar la narración, señalaría que me es difícil imaginar un volumen con sólo tres facetas; sé que hay más: una de ellas ciertamente es la del papel del lector. Quizá por ahí podemos compartir del acto de articular mejor las dos dimensiones tratadas. Gracias. 
